\title{
Karakteristik Kompetensi Guru Dari Perspektif Siswa
}

\author{
Larasati $^{1}$, Mahatma ${ }^{2}$ \\ ${ }^{12}$ Universitas Panca Sakti Bekasi \\ Email:larasati.ups@gmail.com ${ }^{1}$, muhamad.mahatma@gmail.com ${ }^{2}$
}

\begin{abstract}
The purpose of this research is to identify the characteristics of teacher competence that are preferred by the students or according to the students' point of view. This research was conducted from June to July 2021. The method used in this research is quantitative method with survey technique. The survey was conducted through a google form in the form of a questionnaire. There are 110 respondents who filled out the questionnaire in the study. In the research instrument grid, there are four research variables. The results of this study indicate that students prefer teachers who have professional competence, then the second is personality competence, the third is social competence, and the last is pedagogic competence. According to the student's perspective on pedagogic competence, the teacher is still lacking or good enough. So, for pedagogic competence, teachers must pay attention to or be more creative and innovative in the delivery of learning materials so that they can make the class more fun. This is due to several factors which will be discussed in the discussion.
\end{abstract}

Keyword: Teachers competence

\section{PENDAHULUAN}

Mempunyai kompetensi yang baik merupakan karakteristik yang harus dimiliki oleh seorang guru dalam dunia pendidikan. Bukan hal yang tabu bahwa menjadi seorang guru adalah menjadi seseorang yang memiliki martabat yang tinggi, Hal ini karena profesi guru sangat dihargai dan dihormati. Namun menjadi seorang guru tidaklah mudah mengingat beratnya tanggung jawab dan tugas yang harus diemban, menjadi seorang guru harus siap untuk membimbing, mengarahkan dan juga memotivasi setiap anak didiknya dengan benar. Memiliki kompetensi yang baik merupakan salah satu syarat menjadi guru professional. Karena pada dasarnya guru harus bisa menjadi contoh dan tauladan yang baik bagi setiap orang yang mengenalnya, tidak hanya para siswa maupun lingkungan sekolah saja.

Pendidikan adalah sebuah wadah bagi proses kehidupan seseorang, dimana ia menjalani sebuah proses kehidupan dan belajar mengenai hakikat hidup sehingga mampu menjalankan tugas dengan benar sebagai manusia. Oleh karena itu diyakini bahwa manusia merupakan kholifah di muka bumi yang sudah ditetapkan untuk menjadi pemimpin (Busyaeri \& Muharom, 2016)

Menjadi seorang guru harus sadar bahwa memiliki tugas dan dan peran bagi lingkungan sekitarnya, baik kepada peserta didik, orang tua dan masyarakat. Guru juga memiliki peran dan fungsi bagi pembangunan nasional dalam bidang pendidikan, dengan hal tersebut maka profesi seorang guru perlu dikembangkan agar menjadi profesi yang bermartabat (Rangkuti \& Azis, 2014)

$$
\text { Kompetensi guru merupakan }
$$

komponen utama dalam Pendidikan, dimana profesi tersebut merupakan perpaduan antara kemampuan social, teknologi ,keilmuan, dan spiritual dengan menyeluruh. Seorang ahli mengatakan bahwa "Kemampuan yang dimiliki atau dikuasai oleh seseorang, sehingga orang tersebut bisa menerapkan aspek kognitif, aspek afektif, maupun aspek psikomotorik dengan baik atau benar" (Lase, 2016) dalam kompetensi guru mencakup empat kompetensi yaitu, kempetensi pedagogic, kompetensi kepribadian, kompetensi professional, dan kompetensi social.

Kompetensi pedagogik merupakan kemampuan guru dalam memahami karakteristik para siswa dengan perilaku dan sifat yang berbeda-beda, mampu merancang sebuah strategi pembelajaran yang efektif dan menyenangkan di dalam kelas, serta mampu menguasai bahan ajar ilmu pengetahuan secara keseluruhan. Memberikan contoh yang baik, mau memberi suatu nasehat, dan menegur kepada anak murid adalah salah satu kegiatan atau keaktifan dalam kompetensi pedagogik (Wahyu B.S, 2018)

Kompetensi kepribadian adalah kemampuan seorang guru yang tercermin 
dalam kehidupan sehari-harinya, perilaku tersebut mencakup sifat dan karakter pada pembawaan guru tersebut. Sifat yang erat kaitanya adalah sifat jujur, berakhlak mulia, mempunyai etos kerja yang tinggi, dan mempunyai rasa kepedulian terhadap sesama. Salah satu ahli menggungkapkan bahwa "Menjadi seorang guru juga harus memiliki sifat yang jujur dalam berbagai hal, dan bisa menjadi contoh yang baik bagi semua orang. Dan tentunya guru juga harus mempunyai karakter dan kompetensi yang baik didalam maupun diluar sekolah" (Sudirman, 2019)

Kompetensi professional adalah kemampuan guru dalam menguasai dan melaksanakan proses pembelajaran. Dalam hal tersebut guru harus bisa mengikuti kurikulum yang dipakai dalam satuan Pendidikan, serta guru harus menguasai standar kompetensi dan kompetensi dasar. Guru yang professional seharusnya guru yang terampil dan mampu menjalankan tugas serta tanggung jawabnya. Kompetensi profesional seorang guru menunjukkan seperangkat kemampuan yang dimiliki oleh seorang guru agar dapat melaksanakan tugas mengajarnya dengan berhasil (Rosita et al., 2020)

Kompetensi social adalah kemampuan guru dalam berkomunikasi secara baik kepada peserta didik, orang tua wali murid, teman sesama guru, tenaga kependidikan di sekolah, dan lain sebagainya. Guru harus mampu berkomunikasi secara santun dan empati, tidak hanya menjelaskan materi pelajaran dengan baik tetapi juga mampu bersosialisai terhadap semua orang yang mengenalnya, mengingat bahwa seorang guru merupakan pilar contoh yang baik. Seorang guru tentunya memiliki peranan yang besar bagi sebuah Pendidikan, karena guru juga merupakan salah satu factor berkembangnya sebuah negara. Kompetensi sosial terkait dengan kemampuan guru sebagai makhluk sosial dalam berinteraksi dengan orang lain (Sumitra et al., 2018)

Seorang guru mempunyai peranan yang sangat besar bagi majunya sebuah negara dan pekerjaan menjadi seorang guru sangat mulia serta sangat dihormati di kalangan masyarakat. Seorang guru sangat berjasa besar bagi anak didiknya, masyarakat, dan juga negara. Sebagai seorang pendidik peran guru sangat mempengaruhi perkembangan suatu negara, serta sangat menentukan maju mundurnya tingkat kebudayaan di kalangan masyarakat (Oktradiksa, 2012)

Dunia pendidikan sebagai sarana transmisi ataupun sarana bagi kehidupan seseorang. pendidikan memiliki peranan yang sangat besar, dengan Pendidikan tesebut manusia harus mampu mengambil pelajaran ataupun pengalaman yang nantinya bermanfaat untuk kehidupanya.(Anwar, 2017) serta pendidikan harus bisa menanamkan dan mengembangkan karakter bagi bangsa, Pendidikan karakter sangatlah penting bagi kehidupan manusia, dengan hal tersebut dunia Pendidikan tentunya tidak hanya mengajarkan mengenai pengetahuan saja melainkan juga menanamkan suatu Pendidikan moral. (Sudrajat, 2011)

Setiap guru memiliki kompetensi yang berbeda-beda, namun menjadi seorang guru harus bisa membimbing, mengarahkan, dan juga memberikan motivasi terhadap setiap anak didiknya. Selanjutnya adalah bagaimana kompetensi seorang guru yang yang kompeten menurut sudut pandang siswa? Apakah hanya guru-guru yang humoris atau memiliki jiwa kepemimpinan yang tinggi saja yang dimaksud dengan guru yang kompeten atau ada hal-hal lain yang disukai oleh para siswa mengenai karakter atau kepribadian guru yang kompeten, mengingat setiap anak didik memiliki pandangaan dan penilaian yang tidaklah sama. Penelitian ini akan membahas mengenai bagaimana karakteristik kompetensi guru dari perspektif siswa? kompetensi guru yang seperti apa yang diinginkan oleh para siswa?

\section{METODE PENELITIAN}

Penelitian ini bersifat deskriptif dalam bentuk Survey (Sugiyono, 2012) yaitu menggambarkan kompetensi guru yang bagaimanakah yang baik menurut perspektif siswa. Survey itu sendiri sudah banyak digunakan oleh berbagai kalangan mulai dari para ahli, mahasiswa, maupun dalam kalangan masyarakat. (Adiyanta, 2019)

Penelitian ini di lakukan pada bulan juni sampai bulan juli tahun 2021, dan penelitian ini dilakukan di salah satu sekolah swasta yaitu Sekolah Menengah Pertama 
Walisongo Bekasi. Teknik dalam penelitian ini menggunakan kuisioner melalui google form. Dengan google form tersebut peneliti mengajukan pertanyaan kepada responden sebanyak 12 pertanyaan yang berkaitan dengan kompetensi guru. Total populasi seluruhnya adalah 124 siswa dari jumlah tersebut terdapat 110 responden penelitian yang dilakukan,

\section{HASIL PENELITIAN DAN PEMBAHASAN}

Yang membedakan antara guru yang satu dengan guru yang lainya adalah ketika ia mengajar didalam kelas, dengan begitu sifat seorang guru menjadi sebuah ciri khas ataupun karakteristik yang dimiliki oleh seorang guru yang berkaitan dalam proses pembelajaran (Mustofa \& Saifulloh, 2017). Sedangkan pengertian mengenai kompetensi adalah seseorang yang diberikan tugas dan ia mampu mewujudkan tugas tersebut. (Yusuf \& Suci, 2018)

Perlu disadari bahwa menjadi seorang guru harus memiliki keahlian khusus dalam mengemban profesi atau jabatan tersebut. Menjadi seorang guru juga harus memenuhi syarat-syarat khusus. Apalagi guru yang mempunyai kompetensi professional maka harus mengerti betul tentang Pendidikan dengan berbagai ilmu pengetahuan lainya. (Mariyana, 2016)

Dalam penelitian ini, kompetensi guru dibedakan menjadi empat kompetensi yang berkaitan dengan kompetensi guru profesional. Kompetensi tersebut adalah kompetensi pedagogik, kompetensi kepribadian, kompetensi professional, dan kompetensi sosial yang semuanya mengacu pada kompetensi guru. Tabel berikut merupakan hasil penelitian :

\begin{tabular}{|c|c|c|c|}
\hline No & Kompetensi guru & Skor & Ket \\
\hline 1 & Kompetensi profesional & 4,3 & Baik \\
\hline 2 & Kompetensi kepribadian & 4,2 & Baik \\
\hline 3 & Kompetensi Sosial & 4,2 & Baik \\
\hline 4 & Kompetensi Pedagogik & 3,7 & Cukup \\
\hline
\end{tabular}

Tabel. 1 Analisa survey kompetensi guru
Keterangan diatas menunjukan bahwa angka 1 adalah sangat tidak baik, angka 2 adalah tidak baik, angka 3 adalah cukup, angka 4 adalah baik, dan angka 5 adalah sangat baik.

Dalam variabel diatas rata-rata yang paling tinggi terdapat pada kompetensi professional yaitu sebanyak 4,3 yang artinya adalah baik. Jadi menurut perspektif siswa, mereka paling menyukai guru yang mempunyai kompetensi professional. Kompetensi profesional adalah kemampuan penguasaan materi pelajaran secara luas dan mendalam (Hasan, 2017).

Kompetensi profesional seorang guru adalah seperangkat kemampuan yang harus dimiliki oleh sorang guru agar ia dapat melaksanakan tugas mengajar dengan berhasil sesuai dengan tujuan pendidikan (Rahmawati, 2014)

Pendidik atau guru dan tenaga kependidikan merupakan wadah yang sangat penting bagi suatu instansi sekolah, dengan adanya keprofesionalan antara keduanya akan membantu berjalanya proses pendidikan. Kompetensi professional itu sendiri pun sudah dikemukakan oleh para ahli, bahwa menjadi seorang pendidik ataupun tenaga kependidikan memiliki tugas dan tanggung jawab yang harus diemban.

Kompetensi kepribadian menunjukan bahwa mendapatkan skor sebesar 4,2 yang menunjukan keterangan baik. Menurut para siswa, bapak dan ibu guru memiliki kepribadian yang baik dan tentunya dengan kepribadian tersebut bisa memberikan contoh yang baik pula kepada semua peserta didik. Kepribadian guru dapat berpengaruh untuk sikap peserta didiknya. Guru merupakan factor yang pertama dalam proses pembelajaran yang dilakukan oleh siswa, karena guru merupakan contoh bagi para siswanya (Cahyani \& Andriani, 2014)

Guru dengan kompetensi kepribadian yang baik akan sangat membantu dalam upaya pengembangan karakter pada siswa. (Dwintari, 2017) sedangkan kepribadian adalah sesuatu sikap atau tingkah laku yang dimiliki oleh seseorang dalam melaksanakan suatu kegiatan yang menjadi tanggung-jawabnya untuk menentukan suatu tujuan (Darojah \& Hadijah, 2016). 
Selanjutnya kompetensi sosial yang mendapatkan skor sebesar 4,2 dengan keterangan baik. Kompetensi sosial didefinisikan sebagai suatu kemampuan pendidik sebagai bagian dari masyarakat untuk berkomunikasi dan bergaul secara efektif dengan peserta didik, sesama pendidik, tenaga kependidikan, orang tua atau wali peserta didik dan masyarakat sekitar. (Cahyani \& Andriani, 2014)

Yang terakhir adalah kompetensi pedagogik, kompetensi pedagogik guru adalah proses siswa dapat mengerti atau menyadari bahwa lingkungan belajarnya memberikan gambaran atas kecakapan dan kesiapan seorang guru dalam menyampaikan pembelajaranya. (Lambok Simamora, 2014).

Tabel diatas menunjukan nilai kompetensi pedagogic adalah 3,7 yang artinya adalah cukup atau sedang, terdapat beberapa factor yang menunjukan bahwa untuk kompetensi pedagogic ini hanya cukup menurut perspektif siswa, diantaranya adalah para guru disekolah menyampaikan materi secara mononton sehingga siswa merasa bosan belajar didalam kelas, dan seharusnya guru harus lebih efektif dan kreatif dalam menyampaikan materi pelajaran. Seorang ahli mengemukakan bahwa Guru harus lebih kreatif dalam pengelolaan kelas, guru juga harus bisa menguasai materi pembelajaran secara keseluruhan dan menggunakan model pembelajaran yang sesuai dengan bahan pelajaran (Saragih, 2008)

Kurang fokusnya siswa dalam proses pembelajaran yang berlangsung atau siswa tidak bisa berkonsentrasi dengan baik, hal tersebut harus menjadi motivasi untuk para guru agar lebih kreatif dan inovatif dalam memilih model pembelajaran yang menyenangkan untuk para siswa sehingga suasana dikelas juga nyaman dan disukai para siswa.

\section{KESIMPULAN}

Dapat disimpulkan bahwa siswa lebih menyukai dan menginginkan guru dengan kompetensi professional. Dan mereka menganggap bahwa komptensi pedagogic yaitu sedang atau cukup. Dari sudut pandang siswa, pembelajaran yang dilakukan selama ini sangat mononton dan kurang menarik, sehingga siswa cenderung merasa bosan. Keterampilan mengajar guru sangat mempengaruhi motivasi belajar siswa maka guru harus lebih meningkatkan lagi kompetensi pedagogik mereka dalam hal pengetahuan maupun pengelolaan kelas.

\section{UCAPAN TERIMAKASIH}

Ucapan terima kasih disampaikan kepada semua pihak yang telah berperan dalam pembuatan artikel penelitian berjudul Karakteristik kompetensi guru dari perspektif siswa. Sehingga penelitian ini dapat dituangkan dalam bentuk tulisan dan bisa diinformasikan kepada masyarakat Indonesia dan dalam dunia pendidikan khususnya.

\section{DAFTAR PUSTAKA}

Adiyanta, F. C. S. (2019). Hukum dan Studi Penelitian Empiris: Penggunaan Metode Survey sebagai Instrumen Penelitian Hukum Empiris. Administrative Law and Governance Journal, 2(4), 697-709. https://doi.org/10.14710/alj.v2i4.697-709

Anwar, M. K. (2017). Pembelajaran Mendalam untuk Membentuk Karakter Siswa sebagai Pembelajar. Tadris: Jurnal Keguruan Dan Ilmu Tarbiyah, 2(2), 97. https://doi.org/10.24042/tadris.v2i2.1559

Busyaeri, A., \& Muharom, M. (2016). Pengaruh Sikap Guru Terhadap Pengembangan Karakter (Peduli Sosial) Siswa Di Mi Madinatunnajah Kota Cirebon. Al Ibtida: Jurnal Pendidikan Guru MI, 2(1), 1-17. https://doi.org/10.24235/al.ibtida.snj.v2i 1.177

Cahyani, F. D. \&, \& Andriani, F. (2014). Hubungan Antara Persepsi Siswa Terhadap Kompetensi Pedagogik , Kompetensi Kepribadian , Dan Kompetensi Sosial Guru dengan Motivasi Berprestasi Siswa Akselerasi Di SMA Negeri I Gresik. Jurnal Psikologi Pendidikan Dan Perkembangan, 3(2), 78-88.

Darojah, N. R., \& Hadijah, H. S. (2016). Analisis Pengaruh Kompetensi Kepribadian Guru Dengan Motivasi Belajar Sebagai Variabel Intervening 
Terhadap Prestasi Belajar Siswa Kelas X Administrasi Perkantoran. Jurnal Pendidikan Manajemen Perkantoran, l(1), 109. https://doi.org/10.17509/jpm.v1i1.3344

Dwintari, J. W. (2017). Kompetensi Kepribadian Guru dalam Pembelajaran Pendidikan Kewarganegaraan Berbasis Penguatan Pendidikan Karakter. Jurnal Pendidikan Kewarganegaraan, 7, 51-57. https://ppjp.ulm.ac.id/journal/index.php/ pkn/article/view/4271

Hasan, M. (2017). Pengaruh Kompetensi Profesional Guru Terhadap Kinerja Guru Ekonomi Sekolah Menengah Atas Negeri Di Kabupaten Gowa. Jurnal Economix, 5(2), 72-73.

LAMBOK SIMAMORA. (2014). Pengaruh Persepsi Siswa Tentang Kompetensi Pedagogik Guru Dan Kebiasaan Belajar Siswa. Jurnal Formatif 4(1): 21-30, 2014 ISSN: 2088-351X, 4(1), 21-30. lambok@seid.sharp-world.com

Lase, F. (2016). Kompetensi Kepribadian Guru Profesional. Jurnal PPKn Dan Hukum, 11(1), 36-66. https://ejournal.unri.ac.id/index.php/JPB/ article

Mariyana, R. (2016). Kompetensi Guru Dalam Pembelajaran Berbasis Pendidikan Karakter Untuk Anak Usia Dini. PEDAGOGIA Jurnal Ilmu Pendidikan, 12(1), https://doi.org/10.17509/pedagogia.v12i 1.3296

Mustofa, A., \& Saifulloh, R. (2017). Ali Mustofa dan Ragil Saifulloh ,. Jurnal Qolamuna, 3(1), 79-100.

Oktradiksa, A. (2012). Pengembangan Kualitas Kepribadian Guru. Nadwa, 6(2), 231. https://doi.org/10.21580/nw.2012.6.2.59 0

Rahmawati, D. (2014). Peningkatkan Kompetensi Profesional Calon Guru Melalui Lesson Study. AKSIOMA Journal of Mathematics Education, 3(1), 28-33. https://doi.org/10.24127/ajpm.v3i1.378

RANGKUTI, A. A., \& AZIS, H. A. (2014). Gambaran Karakteristik Kepribadian Dan
Nilai Guru Efektif Yang Disukai Berdasarkan Perspektif Siswa Sekolah Negeri Di Jakarta Timur. JPPP - Jurnal Penelitian Dan Pengukuran Psikologi, 3(2), 74-79. https://doi.org/10.21009/jppp.032.05

Rosita, E., Erihadiana, M., Rochman, C., \& Mansyur, A. S. (2020). Kompetensi profesional dan karakteristik guru pada masa pandemik. Ta'dibuna: Jurnal Pendidikan Islam, 9(2), 314. https://doi.org/10.32832/tadibuna.v9i2.3 124

Saragih, A. H. (2008). Kompetensi Minimal Seorang Guru Dalam Mengajar. Jurnal Tabularasa, 5(1), 23-34.

Sudirman, H. S. (2019). Strategi Implementasi Kurikulum: Suatu Kajian Perspektif Teori Di Sekolah Dasar. Adaara: Jurnal Manajemen Pendidikan Islam, 9(2), 936951. https://doi.org/10.35673/ajmpi.v9i2.428

Sudrajat, A. (2011). Mengapa Pendidikan Karakter. Jurnal Pendidikan Karakter, I(1), 47-58. https://doi.org/10.21831/jpk.v1i1.1316

Sumitra, A., Nuraeni, L., \& Nafiqoh, H. (2018). Efektivitas Diklat Berjenjang Tingkat Dasar Terhadap Peningkatan Kompetensi Sosial Pendidik Paud (Studi Deskriptif Pada Pendidik Paud Di Kota Cimahi). P2M STKIP Siliwangi, 5(1), 11. https://doi.org/10.22460/p2m.v5i1p1120.785

Wahyu B.S. (2018). Pengaruh kemampuan pedagogik guru dengan hasil belajar ips. Ilmiah Edutecno, 18(106), 1-19.

Yusuf, T., \& Suci, G. (2018). Pengaruh Kompetensi Profesional Guru, Motivasi Kerja, Dan Disiplin Kerja Terhadap Kinerja Guru Smk Negeri 2 Penajam Paser Utara. Jurnal GeoEkonomi, 9(2), 117-132. https://doi.org/10.36277/geoekonomi.v9i 2.23 